OPEN ACCESS

Check for updates

\title{
Maternal and fetal outcomes following exposure to duloxetine in pregnancy: cohort study
}

\author{
Krista F Huybrechts, ${ }^{1}$ Brian T Bateman, ${ }^{1,2}$ Ajinkya Pawar, ${ }^{1}$ Lily G Bessette, ${ }^{1}$ Helen Mogun, ${ }^{1}$ \\ Raisa Levin, ${ }^{1} \mathrm{Hu} \mathrm{Li}^{3}{ }^{3}$ Stephen Motsko, ${ }^{3}$ Maria Fernanda Scantamburlo Fernandes, ${ }^{3}$ \\ Himanshu P Upadhyaya, ${ }^{3}$ Sonia Hernandez-Diaz ${ }^{4}$
}

\begin{abstract}
${ }^{1}$ Division of
Pharmacoepidemiology

and Pharmacoeconomics,

Department of Medicine,

Brigham and Women's Hospital

and Harvard Medical School,

Boston, MA, USA

${ }^{2}$ Department of Anesthesiology,

Perioperative and Pain

Medicine, Brigham and

Women's Hospital and Harvard

Medical School, Boston, MA,

USA

${ }^{3}$ Eli Lilly and Company,

Indianapolis, IN, USA

${ }^{4}$ Department of Epidemiology, Harvard T.H. Chan School of

Public Health, Boston, MA, USA

Correspondence to:

KF Huybrechts

khuybrechts@bwh.harvard.edu (ORCID 0000-0003-4052-1647)

Additional material is published online only. To view please visit the journal online.

Cite this as: $B M J$ 2020;368:m237 http://dx.doi.org/10.1136/bmj.m237

Accepted: 8 January 2020
\end{abstract}

\section{ABSTRACT}

OBJECTIVE

To evaluate the risk of adverse maternal and infant outcomes following in utero exposure to duloxetine.

DESIGN

Cohort study nested in the Medicaid Analytic eXtract for 2004-13.

SETTING

Publicly insured pregnancies in the United States.

\section{PARTICIPANTS}

Pregnant women 18 to 55 years of age and their liveborn infants.

\section{INTERVENTIONS}

Duloxetine exposure during the etiologically relevant time window, compared with no exposure to duloxetine, exposure to selective serotonin reuptake inhibitors, exposure to venlafaxine, and exposure to duloxetine before but not during pregnancy.

\section{MAIN OUTCOME MEASURES}

Congenital malformations overall, cardiac malformations, preterm birth, small for gestational age infant, pre-eclampsia, and postpartum hemorrhage.

RESULTS

Cohort sizes ranged from 1.3 to 4.1 million, depending on the outcome. The number of women exposed to duloxetine varied by cohort and exposure contrast and was around 2500-3000 for early pregnancy exposure and 900-950 for late pregnancy

\section{WHAT IS ALREADY KNOWN ON THIS TOPIC}

The US Food and Drug Administration requested the manufacturer of duloxetine to set up an pregnancy exposure registry following its approval for the management of fibromyalgia in June 2008

Despite aggressive outreach efforts, enrollment in the registry has not reached its goal, so additional information is needed to meet the post-marketing requirements

More data are needed support conclusions about the safety of duloxetine with respect to congenital malformations and other adverse pregnancy outcomes

\section{WHAT THIS STUDY ADDS}

This large cohort study shows that duloxetine exposure during pregnancy is unlikely to meaningfully increase the risk of congenital malformations overall, preterm birth, or pre-eclampsia

Findings suggest an increased risk of postpartum hemorrhage and a potential small increase in the risk of congenital cardiac malformations and small for gestational age infants

These potential small increases in risk of relatively uncommon outcomes must be weighed against the benefits of treating depression and pain during pregnancy exposure. The base risk per 1000 unexposed women was 36.6 (95\% confidence interval 36.3 to 36.9 ) for congenital malformations overall, 13.7 (13.5 to 13.9$)$ for cardiovascular malformations, 107.8 (107.3 to 108.3$)$ for preterm birth, 20.4 (20.1 to 20.6) for small for gestational age infant, 33.6 (33.3 to 33.9) for pre-eclampsia, and 23.3 (23.1 to 23.4) for postpartum hemorrhage. After adjustment for measured potential confounding variables, all baseline characteristics were well balanced for all exposure contrasts. In propensity score adjusted analyses versus unexposed pregnancies, the relative risk was 1.11 (95\% confidence interval 0.93 to 1.33 ) for congenital malformations overall and 1.29 (0.99 to 1.68) for cardiovascular malformations. For preterm birth, the relative risk was 1.01 (0.92 to 1.10) for early exposure and 1.19 (1.04 to 1.37) for late exposure. For small for gestational age infants the relative risks were 1.14 (0.92 to 1.41) and 1.20 (0.83 to 1.72) for early and late pregnancy exposure, respectively, and for pre-eclampsia they were 1.12 (0.96 to 1.31) and 1.04 ( 0.80 to 1.35$)$. The relative risk for postpartum hemorrhage was 1.53 (1.08 to 2.18). Results from sensitivity analyses were generally consistent with the findings from the main analyses.

\section{CONCLUSIONS}

On the basis of the evidence available to date, duloxetine is unlikely to be a major teratogen but may be associated with an increased risk of postpartum hemorrhage and a small increased risk of cardiac malformations. While continuing to monitor the safety of duloxetine as data accumulate over time, these potential small increases in risk of relatively uncommon outcomes must be weighed against the benefits of treating depression and pain during pregnancy in a given patient.

TRIAL REGISTRATION

EUPAS 15946.

\section{Introduction}

Duloxetine is a selective serotonin-norepinephrine reuptake inhibitor (SNRI), which was first approved in the United States in August 2004. In addition to depression, it is indicated for the treatment of neuropathic pain associated with diabetic peripheral neuropathy, generalized anxiety disorder, fibromyalgia, and chronic musculoskeletal pain in the US. These conditions often affect women of childbearing age, and drug treatment of these conditions in pregnancy is common given the risks associated with untreated depression, anxiety, and pain. ${ }^{1}$ The US Food and Drug Administration therefore requested Eli Lilly, the 
manufacturer of duloxetine, to set up an pregnancy exposure registry following its approval for the management of fibromyalgia in June $2008 .^{2}$ However, as is the case for many such registries, ${ }^{3}$ despite aggressive outreach efforts, enrollment has not reached its goal. By August 2019 the Cymbalta Pregnancy Registry had enrolled only 127 women of the target 484.

Limited information from other post-marketing surveillance systems generally suggests a similar pattern of adverse pregnancy outcomes in women using duloxetine during pregnancy compared with the general population. ${ }^{1}$ One multicenter study based on data from national teratogen information services including 168 live births prenatally exposed to duloxetine reported three $(1.8 \%)$ major malformations, which was considered to be within the expected baseline range in that population. ${ }^{4}$ Another study based on the Swedish Birth Registry identified 286 liveborn infants exposed to duloxetine in the first trimester, seven of whom were born with malformations (relative risk of 0.8$){ }^{5}$ A recent review of the literature concluded that the evidence for duloxetine is limited (668 exposed pregnancies) but does not suggest a clinically important increased risk of major congenital malformations, although specific malformation types could not be evaluated. ${ }^{6}$ An analysis of Danish registry data suggested that duloxetine use might be associated with an increased risk of spontaneous abortion. ${ }^{7}$

Given the limitations of spontaneous adverse event reports (for example, under-reporting, no information on the total number of women exposed), the modest size of existing cohort studies, and the small sample size and challenges faced with enrolment in the Cymbalta Pregnancy Registry, additional information is needed to support conclusions about the safety of duloxetine with respect to congenital malformations, as well as other adverse outcomes of pregnancy. This study was conducted to supplement the Cymbalta Pregnancy Registry with other sources of real world evidence on the safety of duloxetine during pregnancy to help to meet the post-marketing requirements as specified in the new drug approval. It evaluates the risk of adverse maternal and infant outcomes following in utero exposure to duloxetine in a large cohort of pregnant women.

The study is registered with the European Network of Centres for Pharmacoepidemiology and Pharmacovigilance as study EUPAS 15946. The full study protocol and report are available for download at http://www.encepp.eu/encepp/openAttachment/ fullProtocol/16045.

\section{Methods}

\section{Data source and study cohorts}

We conducted a cohort study nested in the nationwide Medicaid Analytic eXtract (MAX) from 2004 to 2013. At the time the study was conducted, the latest available year of MAX data was 2013. The MAX dataset contains individual level demographic and insurance enrollment information, as well as data on all medical visits and hospital admissions, diagnoses, and procedures received as an inpatient or an outpatient and all filled outpatient drug prescriptions for Medicaid beneficiaries. Medicaid covers the medical expenses for approximately $50 \%$ of all pregnancies in the US. We linked completed pregnancies in women aged 18 to 55 years to liveborn infants by using a linkage algorithm based on state of residence, Medicaid case number, and date of delivery. Details of the cohort development and procedures implemented to ensure accurate linkage and complete capture of information have previously been described in detail. ${ }^{8}$

Because the etiologically relevant exposure window, the outcome assessment window, and the covariate assessment window differ depending on the outcome of interest, we created four different cohorts by using different Medicaid eligibility requirements for the mother and the offspring (table 1). We required continuous eligibility for Medicaid (without gaps) from the start of the covariate assessment window through the end of the outcome assessment window. In addition, the cohort used to study the risk of congenital malformations excluded pregnancies with a chromosomal abnormality $(n=2667)$ and pregnancies with exposure to a known teratogenic drug (warfarin, antineoplastic agents, lithium, isotretinoin, misoprostol, thalidomide) during the first trimester $(n=2779)$.

\section{Exposure}

We considered women who filled at least one outpatient prescription for duloxetine during the etiologically relevant window to be exposed to duloxetine. For congenital malformations, the etiologically relevant window is the first trimester of pregnancy, coinciding with the period of organogenesis. For postpartum hemorrhage, the hypothesized mechanism by which duloxetine and similar drugs might increase the risk is by depleting platelet serotonin. ${ }^{910}$ Consequently, we defined the etiologically relevant window as the month before the baby's delivery date. For the outcomes of preterm delivery, small for gestational age infant, and pre-eclampsia, two pregnancy exposure periods are potentially etiologically relevant. These outcomes have been associated with abnormalities in placental development, as well as maternal and fetal factors that develop in late pregnancy. We therefore considered exposure during the first 20 weeks of gestation (that is, last menstrual period (LMP) to day 140 of pregnancy), as well as late pregnancy exposure (day 141 of pregnancy to day 245-the time point at which the outcomes can begin to occur) (table 1).

We considered four different reference groups: women not exposed to duloxetine during the etiologically relevant exposure window (to answer questions about the safety of duloxetine versus no drug treatment); women exposed to selective serotonin reuptake inhibitors (SSRIs-to answer questions about the comparative safety of duloxetine versus the most commonly used antidepressant drug class); women exposed to venlafaxine (to answer questions about the comparative safety of duloxetine versus 


\begin{tabular}{|c|c|c|c|c|c|}
\hline $\begin{array}{l}\text { Cohort and } \\
\text { outcome }\end{array}$ & $\begin{array}{l}\text { Medicaid eligibility } \\
\text { requirement: mother }\end{array}$ & $\begin{array}{l}\text { Medicaid eligibility } \\
\text { requirement: offspring }\end{array}$ & $\begin{array}{l}\text { Duloxetine exposure } \\
\text { window }\end{array}$ & $\begin{array}{l}\text { Outcome assessment } \\
\text { window }\end{array}$ & $\begin{array}{l}\text { Covariate } \\
\text { assessment window }\end{array}$ \\
\hline \multicolumn{6}{|l|}{ Cohort 1: } \\
\hline $\begin{array}{l}\text { Congenital } \\
\text { malformations }\end{array}$ & $\begin{array}{l}90 \text { days before LMP to } 30 \\
\text { days after delivery }\end{array}$ & $\begin{array}{l}3 \text { months after delivery } \\
\text { (unless died) }\end{array}$ & $\begin{array}{l}\text { Dispensed in first } \\
\text { trimester }\end{array}$ & $\begin{array}{l}\text { Delivery to } 3 \text { months } \\
\text { after delivery }\end{array}$ & $\begin{array}{l}90 \text { days before LMP to } \\
\text { end of first trimester }\end{array}$ \\
\hline \multicolumn{6}{|l|}{ Early exposure } \\
\hline \multicolumn{6}{|l|}{ Cohort 2: } \\
\hline Preterm birth & $\begin{array}{l}90 \text { days before LMP to } 30 \\
\text { days after delivery }\end{array}$ & $\begin{array}{l}1 \text { month after delivery } \\
\text { (unless died) }\end{array}$ & $\begin{array}{l}\text { Dispensed LMP to } \\
\text { LMP }+140\end{array}$ & $\begin{array}{l}\text { Delivery to } 1 \text { month } \\
\text { after delivery }\end{array}$ & $\begin{array}{l}90 \text { days before } L M P \text { to } \\
L M P+140\end{array}$ \\
\hline $\begin{array}{l}\text { Small for gestational } \\
\text { age infant }\end{array}$ & $\begin{array}{l}90 \text { days before LMP to } 30 \\
\text { days after delivery }\end{array}$ & $\begin{array}{l}1 \text { month after delivery } \\
\text { (unless died) }\end{array}$ & $\begin{array}{l}\text { Dispensed LMP to } \\
\text { LMP }+140\end{array}$ & $\begin{array}{l}\text { Delivery to } 1 \text { month } \\
\text { after delivery }\end{array}$ & $\begin{array}{l}90 \text { days before } L M P \text { to } \\
L M P+140\end{array}$ \\
\hline \multicolumn{6}{|l|}{ Cohort 3: } \\
\hline Pre-eclampsia & $\begin{array}{l}90 \text { days before LMP to } 30 \\
\text { days after delivery }\end{array}$ & None & $\begin{array}{l}\text { Dispensed LMP to } \\
\text { LMP }+140\end{array}$ & Delivery admission & $\begin{array}{l}90 \text { days before } L M P \text { to } \\
L M P+140\end{array}$ \\
\hline \multicolumn{6}{|l|}{ Late exposure } \\
\hline \multicolumn{6}{|l|}{ Cohort 2: } \\
\hline Preterm birth & $\begin{array}{l}90 \text { days before LMP to } 30 \\
\text { days after delivery }\end{array}$ & $\begin{array}{l}1 \text { month after delivery } \\
\text { (unless died) }\end{array}$ & $\begin{array}{l}\text { Dispensed LMP+141 to } \\
\mathrm{LMP}+245\end{array}$ & $\begin{array}{l}\text { Delivery to } 1 \text { month } \\
\text { after delivery }\end{array}$ & $\begin{array}{l}90 \text { days before } L M P \text { to } \\
L M P+245\end{array}$ \\
\hline $\begin{array}{l}\text { Small for gestational } \\
\text { age infant }\end{array}$ & $\begin{array}{l}90 \text { days before LMP to } 30 \\
\text { days after delivery }\end{array}$ & $\begin{array}{l}1 \text { month after delivery } \\
\text { (unless died) }\end{array}$ & $\begin{array}{l}\text { Dispensed LMP+141 to } \\
L M P+245\end{array}$ & $\begin{array}{l}\text { Delivery to } 1 \text { month } \\
\text { after delivery }\end{array}$ & $\begin{array}{l}90 \text { days before LMP to } \\
L M P+245\end{array}$ \\
\hline \multicolumn{6}{|l|}{ Cohort 3: } \\
\hline Pre-eclampsia & $\begin{array}{l}90 \text { days before LMP to } 30 \\
\text { days after delivery }\end{array}$ & None & $\begin{array}{l}\text { Dispensed LMP+141 to } \\
L M P+245\end{array}$ & $\begin{array}{l}\text { Delivery } \\
\text { admission }\end{array}$ & $\begin{array}{l}90 \text { days before } L M P \text { to } \\
L M P+245\end{array}$ \\
\hline \multicolumn{6}{|l|}{ Cohort 4: } \\
\hline $\begin{array}{l}\text { Postpartum } \\
\text { hemorrhage }\end{array}$ & $\begin{array}{l}4 \text { months before } \\
\text { delivery to } 1 \text { month } \\
\text { after delivery }\end{array}$ & None & $\begin{array}{l}\text { Dispensed } 1 \text { month be- } \\
\text { fore delivery to delivery }\end{array}$ & $\begin{array}{l}\text { Delivery } \\
\text { admission }\end{array}$ & $\begin{array}{l}4 \text { months before } \\
\text { delivery to } 1 \text { day } \\
\text { before delivery }\end{array}$ \\
\hline
\end{tabular}

another SNRI); and, for the outcome of malformations, women exposed to duloxetine before but not during pregnancy (to answer questions about the safety of continuation during pregnancy) (table 2). The second and third reference groups are expected to reduce residual confounding, and the third reference group also provides evidence about whether any observed increase in risk is attributable to a SNRI class effect.

\section{Outcomes}

We defined the presence of major congenital malformations by using algorithms based on inpatient or outpatient diagnoses and procedure codes in the maternal (first month after delivery) or infant (first three months after date of birth) record, which have been shown to identify congenital malformations with high specificity (sTable 1$).^{11}{ }^{12}$ Congenital malformations overall and cardiac malformations were the primary malformation outcomes of interest; we considered other malformation types as secondary outcomes because of the anticipated small number of events. We defined preterm delivery by the presence of any inpatient or outpatient codes for preterm birth in the mother or infant record between delivery and delivery+30 days (sTable 2). We defined small for gestational age by the presence of at least one of the ICD-9 (international classification of disease, 9th revision) diagnostic codes $656.5 \mathrm{x}, 764.0 \mathrm{x}, 764.1 \mathrm{x}$, and $764.9 \mathrm{x}$ in maternal or infant claims from delivery to delivery+30 days. We defined pre-eclampsia by the presence of at least one of the ICD-9 diagnostic codes $642.4 \mathrm{x}, 642.5 \mathrm{x}, 642.6 \mathrm{x}$, and $642.7 \mathrm{x}$ in the maternal inpatient claims during the delivery hospital admission. We defined postpartum hemorrhage by the presence of at least one of the ICD-9 diagnostic codes 666.xx in the maternal inpatient claims during the delivery hospital admission. All outcome definitions for the primary outcomes have been validated and shown to have a high positive predictive value. ${ }^{11} 13$

In a sensitivity analysis, we generated de-identified claims profiles of mothers or infants with the outcome of interest as defined using these algorithms for all cases. Expert clinicians reviewed the profiles, blinded to the exposure status, and "adjudicated" each case as the outcome likely occurred, the outcome probably occurred, or the outcome likely did not occur. As we strive for high specificity of the outcome definition, we assessed the effect of including only cases classified as "likely occurred."

\section{Covariates}

We considered six groups of covariates that could potentially confound the association between exposure to duloxetine and the outcomes of interest: maternal demographic characteristics (for example, age, race/ethnicity), medical indications for duloxetine (depression, anxiety, specific pain conditions), comorbid medical conditions (chronic hypertension, diabetes, bipolar disorder, schizophrenia, infections, alcohol and drug misuse or dependence), obstetric characteristics/conditions (multifetal gestation), maternal drug treatment (for example, benzodiazepines, anxiolytics, opioid analgesics, antidiabetes drugs, suspected teratogenic drugs), and measures of healthcare utilization (for example, number of distinct drugs, number of outpatient medical visits) (sTable 3 ). We 


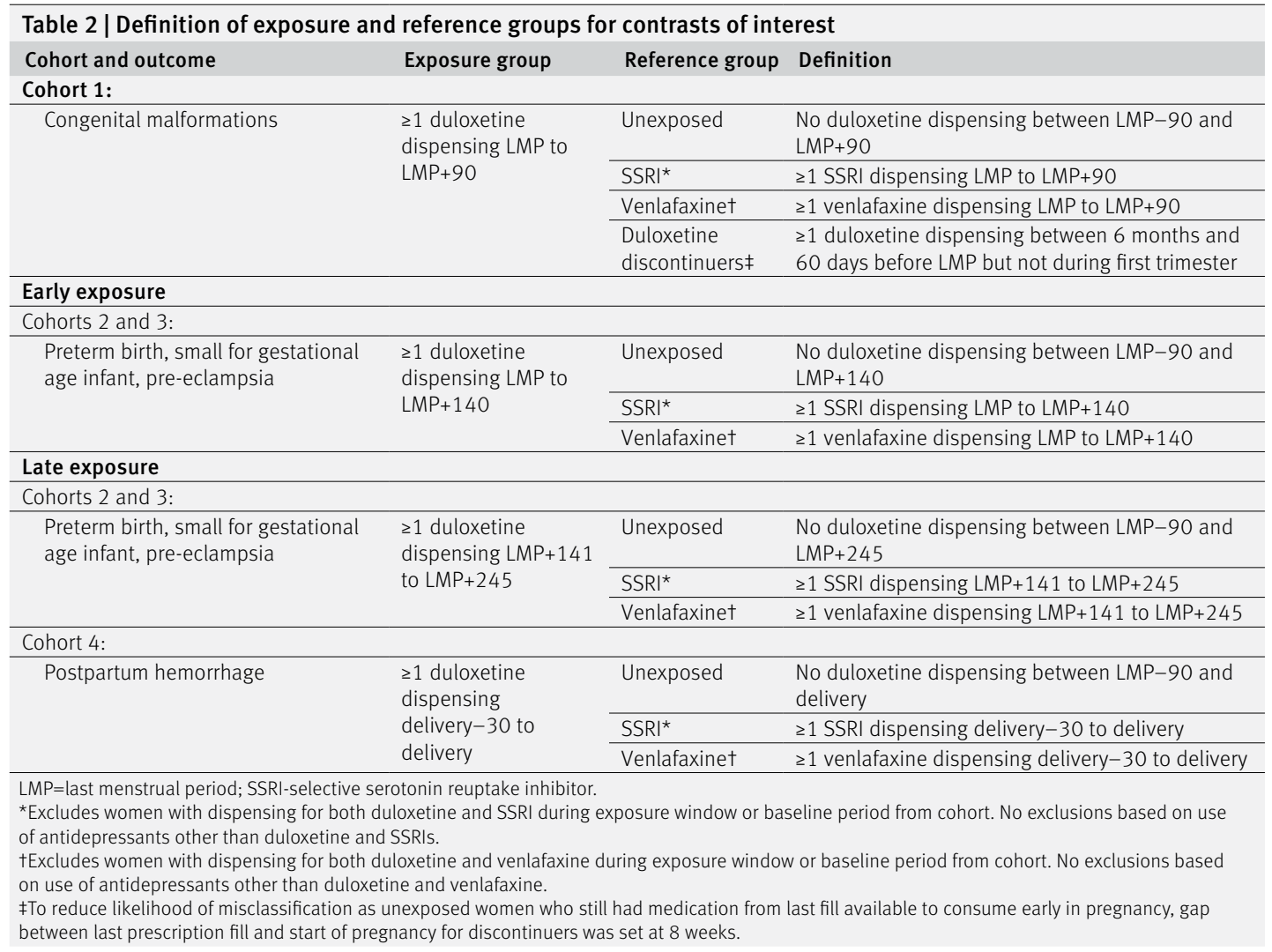

selected the included covariates because they are potential risk factors for the outcomes or potential proxies for such risk factors.

\section{Analyses}

We described baseline characteristics of the study cohorts stratified by exposure group and considered between group standardized mean differences above 0.1 as evidence of imbalance. ${ }^{14}$ For each outcome, we report the number of events, as well as the absolute and relative risks with their 95\% confidence intervals. We present results for four levels of adjustment: unadjusted; restricted to women with recorded depression, anxiety, or specific pain conditions (referred to hereafter as restricted cohort), using propensity score stratification to account for imbalances in the specific indication; restricted cohort, using propensity score stratification to account for imbalances in all predefined potential confounders including indications (referred to as fully adjusted); and restricted cohort, using high dimensional propensity score (hdPS) stratification to further account for imbalances in 200 empirically defined proxies of unmeasured confounders. ${ }^{15}$

We derived propensity scores from the predicted probability of treatment estimated in a logistic regression model, which contained all covariates without additional variable selection. We excluded observations from the non-overlapping regions of the propensity score distributions and defined 50 equally sized propensity score strata based on the distribution among the duloxetine treated women. ${ }^{16}$
In the outcome models, the observations from the reference group were weighted using the distribution of the treated among propensity score strata. We estimated adjusted relative risks by using generalized linear models (SAS PROC GENMOD with a weight statement and loglink function).

We did a broad range of sensitivity analyses to test the robustness of the findings against exposure misclassification, outcome misclassification, residual confounding, and selection bias (table 3 ). We interpreted the overall findings in light of the results of these pre-specified sensitivity analyses. We used SAS version 9.4 for analyses and made no adjustments for multiple comparisons.

\section{Patient and public involvement}

No patients were involved in setting the research question or the outcome measures. No patients were asked to advise on interpretation or writing up of results.

\section{Results}

\section{Characteristics of study cohort}

The source cohort consisted of 8410882 pregnant women aged 18 years or older from 46 US states and Washington DC, with completed pregnancies between July 2004 and December 2013 linked to a liveborn infant. After implementation of the Medicaid eligibility criteria, as well as cohort specific exclusion criteria, the cohort sizes were 1.3-1.5 million for the congenital malformation, preterm birth, small for gestational age, and pre- 


\begin{tabular}{|c|c|c|c|c|c|}
\hline \multirow[b]{2}{*}{ No } & \multicolumn{2}{|c|}{ Misclassification } & \multirow[b]{2}{*}{ Confounding } & \multirow[b]{2}{*}{ Selection bias } & \multirow[b]{2}{*}{ Sensitivity analysis } \\
\hline & Exposure & Outcome & & & \\
\hline \multicolumn{6}{|c|}{ All outcomes } \\
\hline 1 & $\bullet$ & O & O & O & $\begin{array}{l}\text { Re-define exposure as having filled } \geq 2 \text { prescriptions for } \\
\text { duloxetine during etiologically relevant time window }\end{array}$ \\
\hline 2 & $\bullet$ & O & O & O & $\begin{array}{l}\text { Redefine exposure as day's supply that overlaps with } \\
\text { etiologically relevant time window }\end{array}$ \\
\hline 3 & O & O & $\bullet$ & O & $\begin{array}{l}\text { Restrict population to women with recorded diagnosis of } \\
\text { fibromyalgia }\end{array}$ \\
\hline 4 & O & $\bullet$ & O & O & $\begin{array}{l}\text { Probabilistic bias analysis: correct relative risks for outcome } \\
\text { misclassification using sensitivities and specificities consistent } \\
\text { with positive predictive value estimated in validation study }\end{array}$ \\
\hline 5 & O & $\bullet$ & O & O & $\begin{array}{l}\text { Assess effect of excluding outcomes designated as "probably[A: } \\
\text { possibly?] occurred" or “likely did not occur" based on review of } \\
\text { claims profiles }\end{array}$ \\
\hline 6 & O & O & O & O & Restrict cohort to first pregnancy occurring within study period* \\
\hline 7 & O & O & ○ & O & $\begin{array}{l}\text { External adjustment of relative risk to counter potential residual } \\
\text { confounding by obesity, alcohol, and smoking }\end{array}$ \\
\hline \multicolumn{6}{|c|}{ Congenital malformations } \\
\hline 8 & O & - & $\mathrm{O}$ & $\mathrm{O}$ & Re-define outcome based on infant claims only \\
\hline 9 & $\mathrm{O}$ & - & $\mathrm{O}$ & $\mathrm{O}$ & Restrict outcome to inpatient diagnoses only \\
\hline 10 & $\mathrm{O}$ & - & $\mathrm{O}$ & $\mathrm{O}$ & Extend infant follow-up to 1 year \\
\hline 11 & O & O & O & $\bullet$ & $\begin{array}{l}\text { Examine potential effect of differences in proportion of } \\
\text { terminations among women treated with duloxetine versus those } \\
\text { untreated within levels of covariates used in adjustment }\end{array}$ \\
\hline \multicolumn{6}{|c|}{ Postpartum hemorrhage } \\
\hline 12 & - & $\mathrm{O}$ & $\mathrm{O}$ & $\mathrm{O}$ & Day's supply of duloxetine overlapping date of delivery \\
\hline 13 & $\bullet$ & O & O & O & $\begin{array}{l}\text { Classify women with duloxetine dispensed }<14 \text { days before } \\
\text { delivery, regardless of day’s supply on delivery date, as having } \\
\text { current exposure }\end{array}$ \\
\hline
\end{tabular}

eclampsia cohorts and 4.1 million for the postpartum hemorrhage cohort. We have previously shown that minimal differences exist in key clinical and demographic characteristics for pregnant women excluded from the study cohort owing to various eligibility requirements. ${ }^{17}$ The number of women exposed to duloxetine varied by cohort and exposure contrast and was between 2500 and 3000 for first trimester and early pregnancy exposure (defined as LMP to LMP+140 days) and 900 to 950 for exposure late in pregnancy (defined as LMP+141 to LMP+245 days; 30 days before delivery) (table 4).

We observed differences in baseline characteristics between duloxetine exposed women and the reference groups, with the differences being most pronounced for the comparison with unexposed women (41 of 66 distinct covariates showed an imbalance with absolute standardized mean differences >0.1). Duloxetine exposed women tended to be older, were more likely to be white, had a higher burden of chronic comorbid conditions, more frequently used other drugs, and had more intense healthcare utilization. After adjustment for measured potential confounding variables through propensity score stratification, all baseline characteristics were well balanced for all exposure contrasts (table 5; sTables 4-7).

The base risk per 1000 unexposed women was 36.6 (95\% confidence interval 36.3 to 36.9 ) for congenital malformations overall, 13.7 (13.5 to 13.9) for cardiovascular malformations, 107.8 (107.3 to 108.3) for preterm birth, 20.4 (20.1 to 20.6) for small for gestational age infant, 33.6 (33.3 to 33.9) for preeclampsia, and 23.3 (23.1 to 23.4) for postpartum hemorrhage.

\begin{tabular}{|c|c|c|c|c|}
\hline \multirow[b]{2}{*}{ Definition } & \multicolumn{4}{|c|}{ Number of pregnancies } \\
\hline & $\begin{array}{l}\text { Cohort 1: } \\
\text { malformations }\end{array}$ & $\begin{array}{l}\text { Cohort 2: preterm birth/small } \\
\text { for gestational age infant }\end{array}$ & $\begin{array}{l}\text { Cohort 3: } \\
\text { pre-eclampsia }\end{array}$ & $\begin{array}{l}\text { Cohort 4: postpartum } \\
\text { hemorrhage }\end{array}$ \\
\hline Pregnancies 2004-13 & 9079307 & & & \\
\hline Restrict to age $\geq 18$ years & 8410882 & & & \\
\hline Implement maternal eligibility criteria* & 1452823 & 1452823 & 1452823 & 4135740 \\
\hline Implement infant eligibility criteria & 1294742 & 1369189 & - & - \\
\hline Exclude pregnancies with chromosomal abnormality & 1292075 & - & - & - \\
\hline Exclude pregnancies with exposure to definite teratogen & 1289296 & - & - & - \\
\hline $\begin{array}{l}\text { Exclude pregnancies with duloxetine exposure before but } \\
\text { not during etiologically relevant window }\end{array}$ & 1287359 & 1367199 & 1450755 & 4135000 \\
\hline Exposed to duloxetine & 2532 (trimester 1) & 2903 (early); 880 (late) & 3059 (early); 933 (late) & 955 (month before delivery) \\
\hline
\end{tabular}



Table 5 | Selected cohort characteristics of pregnancies with and without exposure to duloxetine during first trimester. Values are numbers
(percentages) unless stated otherwise

\begin{tabular}{|c|c|c|c|c|c|c|}
\hline \multirow[b]{2}{*}{ Characteristic } & \multicolumn{3}{|c|}{ Unadjusted } & \multicolumn{3}{|c|}{ Accounting for propensity score strata } \\
\hline & $\begin{array}{l}\text { Duloxetine } \\
(n=2532)\end{array}$ & $\begin{array}{l}\text { Unexposed } \\
(n=1284827)\end{array}$ & $\begin{array}{l}\text { Standardized } \\
\text { difference* }\end{array}$ & $\begin{array}{l}\text { Duloxetine } \\
(n=2223)\end{array}$ & $\begin{array}{l}\text { Unexposed } \\
(n=392928)\end{array}$ & $\begin{array}{l}\text { Standardized } \\
\text { difference* }\end{array}$ \\
\hline Mean (SD) age, years & $27.74(5.53)$ & $24.93(5.36)$ & 0.51 & $27.81(5.55)$ & $27.76(5.56)$ & 0.01 \\
\hline \multicolumn{7}{|l|}{ Race/ethnicity: } \\
\hline White & $2003(79.1)$ & $518455(40.4)$ & 0.86 & $1761(79.2)$ & $315827(80.4)$ & -0.03 \\
\hline Black or African-American & $219(8.6)$ & $400432(31.2)$ & -0.59 & $193(8.7)$ & $30859(7.9)$ & 0.03 \\
\hline Hispanic or Latino & $70(2.8)$ & $181970(14.2)$ & -0.42 & $61(2.7)$ & $9549(2.4)$ & 0.02 \\
\hline Asian or other Pacific Islander & $32(1.3)$ & $56128(4.4)$ & -0.19 & $30(1.3)$ & $5155(1.3)$ & 0.00 \\
\hline Native American & $33(1.3)$ & $21136(1.6)$ & -0.03 & $29(1.3)$ & $5056(1.3)$ & 0.00 \\
\hline Other & $117(4.6)$ & $75858(5.9)$ & -0.06 & $101(4.5)$ & $18013(4.6)$ & 0.00 \\
\hline Unknown & $58(2.3)$ & $30848(2.4)$ & -0.01 & $48(2.2)$ & $8469(2.2)$ & 0.00 \\
\hline \multicolumn{7}{|l|}{ Chronic comorbid conditions: } \\
\hline Hypertension & $191(7.5)$ & $34556(2.7)$ & 0.22 & $173(7.8)$ & $30313(7.7)$ & 0.00 \\
\hline Diabetes & $152(6.0)$ & $30063(2.3)$ & 0.18 & $135(6.1)$ & $23922(6.1)$ & 0.00 \\
\hline Renal disease & $23(0.9)$ & $4695(0.4)$ & 0.07 & $22(1.0)$ & $3970(1.0)$ & 0.00 \\
\hline Obesity/overweight & $152(6.0)$ & $33501(2.6)$ & 0.17 & $142(6.4)$ & $24906(6.3)$ & 0.00 \\
\hline \multicolumn{7}{|l|}{ Indications for duloxetine: } \\
\hline Depression & $1235(48.8)$ & $77678(6.0)$ & 1.09 & $1234(55.5)$ & $223353(56.8)$ & -0.03 \\
\hline Anxiety & $778(30.7)$ & $52167(4.1)$ & 0.75 & $777(35)$ & $138909(35.4)$ & -0.01 \\
\hline Neuropathic pain & $267(10.5)$ & $20024(1.6)$ & 0.38 & $267(12.0)$ & $46252(11.8)$ & 0.01 \\
\hline Fibromyalgia & $264(10.4)$ & $11829(0.9)$ & 0.42 & $263(11.8)$ & $42201(10.7)$ & 0.03 \\
\hline Non-neuropathic pain & $1234(48.7)$ & $198581(15.5)$ & 0.76 & $1233(55.45)$ & $213645(54.4)$ & 0.02 \\
\hline \multicolumn{7}{|l|}{ Other psychiatric conditions: } \\
\hline Sleep disorder & $144(5.7)$ & $10560(0.8)$ & 0.28 & $136(6.1)$ & $23672(6.0)$ & 0.00 \\
\hline Bipolar disorder & $330(13.0)$ & $17340(1.3)$ & 0.46 & $294(13.2)$ & $50799(12.9)$ & 0.01 \\
\hline Psychosis & $20(0.8)$ & $2570(0.2)$ & 0.08 & $19(0.9)$ & $3359(0.9)$ & 0.00 \\
\hline Schizophrenia & $25(1.0)$ & $2096(0.2)$ & 0.11 & $23(1.0)$ & $4041(1.0)$ & 0.00 \\
\hline Personality disorder & $56(2.2)$ & $2613(0.2)$ & 0.18 & $55(2.8)$ & $9490(2.4)$ & 0.00 \\
\hline Adjustment disorder & $29(1.1)$ & $4620(0.4)$ & 0.09 & $25(1.1)$ & $4382(1.1)$ & 0.00 \\
\hline Tobacco use & $279(11.0)$ & $52341(4.1)$ & 0.27 & $266(12.0)$ & $47559(12.1)$ & 0.00 \\
\hline Alcohol misuse or dependence & $31(1.2)$ & $4744(0.4)$ & 0.10 & $28(1.3)$ & $5054(1.3)$ & 0.00 \\
\hline Drug misuse or dependence & $84(3.3)$ & $11587(0.9)$ & 0.17 & $80(3.6)$ & $14339(3.6)$ & 0.00 \\
\hline \multicolumn{7}{|l|}{ Other drug exposures: } \\
\hline Benzodiazepines & $979(38.7)$ & $46726(3.6)$ & 0.95 & $911(41.0)$ & $160239(40.8)$ & 0.00 \\
\hline Other hypnotics & $608(24.0)$ & $48070(3.7)$ & 0.61 & $563(25.3)$ & $97232(24.7)$ & 0.01 \\
\hline Barbiturates & $124(4.9)$ & $14042(1.1)$ & 0.22 & $111(5.0)$ & $19572(5.0)$ & 0.00 \\
\hline Anxiolytics & $129(5.1)$ & $5852(0.5)$ & 0.29 & $118(5.3)$ & $20392(5.2)$ & 0.01 \\
\hline Anticonvulsants & $642(25.4)$ & $29354(2.3)$ & 0.71 & $590(26.5)$ & $99450(25.3)$ & 0.03 \\
\hline Antipsychotics & $505(19.9)$ & $18630(1.4)$ & 0.63 & $463(20.8)$ & $77907(19.8)$ & 0.02 \\
\hline SSRIS & $705(27.8)$ & $88971(6.9)$ & 0.57 & $645(29.0)$ & $121358(30.9)$ & -0.04 \\
\hline SNRIs & $103(4.1)$ & $10809(0.8)$ & 0.21 & $92(4.1)$ & $17233(4.4)$ & -0.01 \\
\hline Other antidepressants & $720(28.4)$ & $40109(3.1)$ & 0.74 & $667(30.0)$ & $116681(29.7)$ & 0.01 \\
\hline Stimulants & $198(7.8)$ & $10738(0.8)$ & 0.35 & $172(7.7)$ & $29167(7.4)$ & 0.01 \\
\hline Anti-diabetes drugs & $100(3.9)$ & $13468(1.0)$ & 0.19 & $86(3.9)$ & $15036(3.8)$ & 0.00 \\
\hline Insulin & $80(3.2)$ & $12212(1.0)$ & 0.16 & $69(3.1)$ & $12322(3.1)$ & 0.00 \\
\hline Antihypertensives & $373(14.7)$ & $41000(3.2)$ & 0.41 & $329(14.8)$ & $56095(14.3)$ & 0.01 \\
\hline Opioid analgesics & $1554(61.4)$ & $310792(24.2)$ & 0.81 & $1425(64.1)$ & $252815(64.3)$ & 0.00 \\
\hline Triptans & $178(7.0)$ & $15504(1.2)$ & 0.30 & $165(7.4)$ & $28900(7.4)$ & 0.00 \\
\hline NSAIDS & $958(37.8)$ & $221631(17.2)$ & 0.47 & $894(40.2)$ & $157677(40.1)$ & 0.00 \\
\hline Multfetal gestation & $87(3.4)$ & $47282(3.7)$ & -0.01 & $77(3.5)$ & $13572(3.5)$ & 0.00 \\
\hline \multicolumn{7}{|l|}{ Potentially teratogenic drug exposures: } \\
\hline Danazol & $0(0)$ & $21(0)$ & -0.01 & $0(0)$ & $0(0)$ & \\
\hline Synthetic progestins & $88(3.5)$ & $25715(2.0)$ & 0.09 & $80(3.6)$ & $14054(3.6)$ & 0.00 \\
\hline Methimazole & $<11(0.1)$ & $678(0.1)$ & 0.02 & $<11(0.13)$ & $570(0.1)$ & 0.00 \\
\hline Propylthiouracil & $<11(0.2)$ & $1466(0.1)$ & 0.01 & $<11(0.18)$ & $742(0.2)$ & 0.00 \\
\hline Corticosteroids & $453(17.9)$ & $92250(7.2)$ & 0.33 & $402(18.08)$ & $70912(18.0)$ & 0.00 \\
\hline Fluconazole & $133(5.3)$ & $28109(2.2)$ & 0.16 & $115(5.17)$ & $19664(5.0)$ & 0.01 \\
\hline \multicolumn{7}{|l|}{ Mean (SD) healthcare utilization: } \\
\hline Comorbidity index & $1.58(1.85)$ & $0.92(1.40)$ & 0.40 & $1.62(1.88)$ & $1.61(1.85)$ & 0.01 \\
\hline Morphine equivalents & $19774(489396)$ & $754(67877)$ & 0.05 & $21635(521363)$ & $18278(373453)$ & 0.01 \\
\hline No of diagnoses & $5.95(4.65)$ & $2.80(3.33)$ & 0.78 & $6.33(4.70)$ & $6.43(4.77)$ & -0.02 \\
\hline No of ED visits & $0.72(1.30)$ & $0.35(0.89)$ & 0.33 & $0.77(1.32)$ & $0.81(1.66)$ & -0.03 \\
\hline No of generics dispensed & $5.63(4.19)$ & $1.81(2.48)$ & 1.11 & $5.88(4.25)$ & $5.93(4.31)$ & -0.01 \\
\hline No of hospital admissions & $0.05(0.27)$ & $0.04(0.23)$ & 0.05 & $0.06(0.28)$ & $0.06(0.28)$ & 0.01 \\
\hline No of outpatient visits & $5.58(6.43)$ & $2.11(3.43)$ & 0.67 & $5.96(6.62)$ & $5.94(6.38)$ & 0.00 \\
\hline No of psychiatric hospital admissions & $0.04(0.22)$ & $0.01(0.09)$ & 0.17 & $0.04(0.23)$ & $0.04(0.23)$ & 0.01 \\
\hline No of psychiatrist visits & $2.28(4.94)$ & $0.33(2.14)$ & 0.51 & $2.48(5.09)$ & $2.46(5.05)$ & 0.00 \\
\hline
\end{tabular}

$E D=$ emergency department; NSAID=non-steroidal anti-inflammatory drug; SNRI=selective serotonin-norepinephrine reuptake inhibitor; SSRI=selective serotonin reuptake inhibitor. *See supplementary materials (sTables 4-7) for how this was estimated. 


\section{Congenital malformations}

Compared with unexposed women, the risk of major congenital malformations overall in women exposed to duloxetine was increased in unadjusted analyses, with a relative risk of 1.38 (95\% confidence interval 1.17 to 1.64). The relative risk attenuated with increasing levels of adjustment: 1.23 (1.03 to 1.47) after restriction to and adjustment for treatment indications, 1.11 (0.93 to 1.33) after adjustment for all possible confounding variables (full adjustment), and 1.08 (0.91 to 1.30) with hdPS adjustment. We observed similar fully adjusted relative risks for comparisons with the other reference groups (fig 1 and sFigure1). Results from the sensitivity analyses were largely consistent with those from the main analyses, especially when we accounted for the imprecision with which some of the associations are estimated (sFigures 2 and 3).

The fully adjusted relative risk of cardiovascular malformations in women exposed to duloxetine was 1.29 (0.99 to 1.68 ) versus unexposed women, 1.27 (0.93 to 1.74) versus women exposed to SSRIs, 1.17 (0.84 to 1.63 ) versus women exposed to venlafaxine, and 1.41 (0.92 to 2.17) versus duloxetine discontinuers (fig 1). When we redefined exposure on the basis of two dispensings of duloxetine during the first trimester, the fully adjusted risk estimates strengthened: 1.71 (1.21 to 2.41) versus unexposed women, 1.69 (1.11 to 2.56 ) versus SSRI exposed women, 1.38 (0.90 to 2.11 ) versus venlafaxine exposed women, and 2.10 (1.14 to 3.85 ) versus duloxetine discontinuers. Other sensitivity analyses yielded similar results to those from the primary fully adjusted analyses (sFigures 4 and 5).

Results for most other malformation types were consistent with a null finding, except for urinary malformations (fully adjusted relative risk of 1.89 (1.14 to 3.14) for duloxetine exposed versus unexposed women) and malformations not otherwise classified (fully adjusted relative risk of 2.98 (1.41 to 6.29) versus unexposed women) (sFigure 1). However, for both of these malformation categories, the number of events in exposed women was small (15 or fewer for urinary malformations and <11 for other malformations), and inspection of the distribution of ICD-9 diagnostic codes among cases did not identify a clear specific malformation subtype with increased risk.

\section{Preterm birth}

Compared with unexposed women, the risk of preterm birth for women with exposure to duloxetine early in pregnancy was increased in unadjusted analyses (relative risk $1.33,1.22$ to 1.46 ) but not in adjusted analyses (1.01, 0.92 to 1.10 , with full adjustment; $0.99,0.90$ to 1.09 , with hdPS adjustment). The fully adjusted relative risk was 0.95 (0.84 to 1.06) compared with women exposed to SSRIs and 0.94 (0.84 to 1.06) compared with women exposed to venlafaxine. We observed a similar pattern for duloxetine exposure late in pregnancy, except for a somewhat stronger association versus unexposed women (relative risk $1.19,1.04$ to 1.37$)$. These results, along with the sensitivity analyses, are generally consistent with no meaningful increase in risk of preterm birth for either early or late pregnancy exposure (fig 1; sFigures 6-9),

\section{Small for gestational age infants}

In fully adjusted analyses, the relative risk of small for gestational age infants for women with duloxetine exposure early in pregnancy was 1.14 (0.92 to 1.41$)$ compared with unexposed women, 1.26 (0.97 to 1.64) compared with SSRI exposed women, and 1.18 (0.90 to 1.56) compared with venlafaxine exposed women. We observed a similar pattern for exposure late in pregnancy: 1.20 (0.83 to 1.72 ), 1.17 (0.73 to 1.88 ), and 1.32 (0.83 to 2.09) for comparison with unexposed, SSRI exposed, and venlafaxine exposed women, respectively (fig 1). Across the sensitivity analyses, point estimates suggested a small increase but with confidence intervals that generally intersect the null. These results, in aggregate, suggest a potentially small increase in risk of small for gestational age infants with exposure to duloxetine early and late in pregnancy, although the increased risk was not seen consistently across all sensitivity analyses (sFigures 10-13).

\section{Pre-eclampsia}

Compared with unexposed women, the risk of preeclampsia was increased in unadjusted analyses with a relative risk of 1.67 (1.44 to 1.93) for early exposure and 1.85 (1.44 to 2.38) for late exposure. The risk was attenuated in fully adjusted analyses (relative risk 1.12 (0.96 to 1.31 ) for early exposure and 1.04 (0.80 to 1.35) for late exposure). We observed similar adjusted relative risks around the null for comparisons with the other reference groups (fig 1). These results are consistent with no increase in risk of pre-eclampsia for exposure in either early or late pregnancy. Sensitivity analyses were generally consistent with these findings, although when we redefined exposure on the basis of two dispensings during the early exposure window, duloxetine exposure was associated with a small increase in the risk for pre-eclampsia compared with that in unexposed women or those exposed to SSRIs (but not venlafaxine exposed women) (sFigures 14-17).

\section{Postpartum hemorrhage}

Compared with unexposed women, the risk of postpartum hemorrhage in duloxetine exposed women was increased in unadjusted analyses, with a relative risk of 1.53 (1.10 to 2.13). The strength of the association did not change much with increasing levels of adjustment: 1.55 (1.09 to 2.20) after restriction to and adjustment for treatment indication, 1.53 (1.08 to 2.18) after full adjustment, and 1.48 (1.04 to 2.10) with hdPS adjustment. We also observed an increased risk of postpartum hemorrhage compared with women exposed to SSRIs: 1.32 (0.94 to 1.85$)$ in unadjusted analyses, 1.42 (0.99 to 2.03) after restriction to and adjustment for treatment indication, 1.48 (1.03 to 2.12) after full adjustment, and 1.31 (0.91 to 1.87) with hdPS adjustment. In contrast, we saw no increased risk of postpartum hemorrhage compared with venlafaxine 


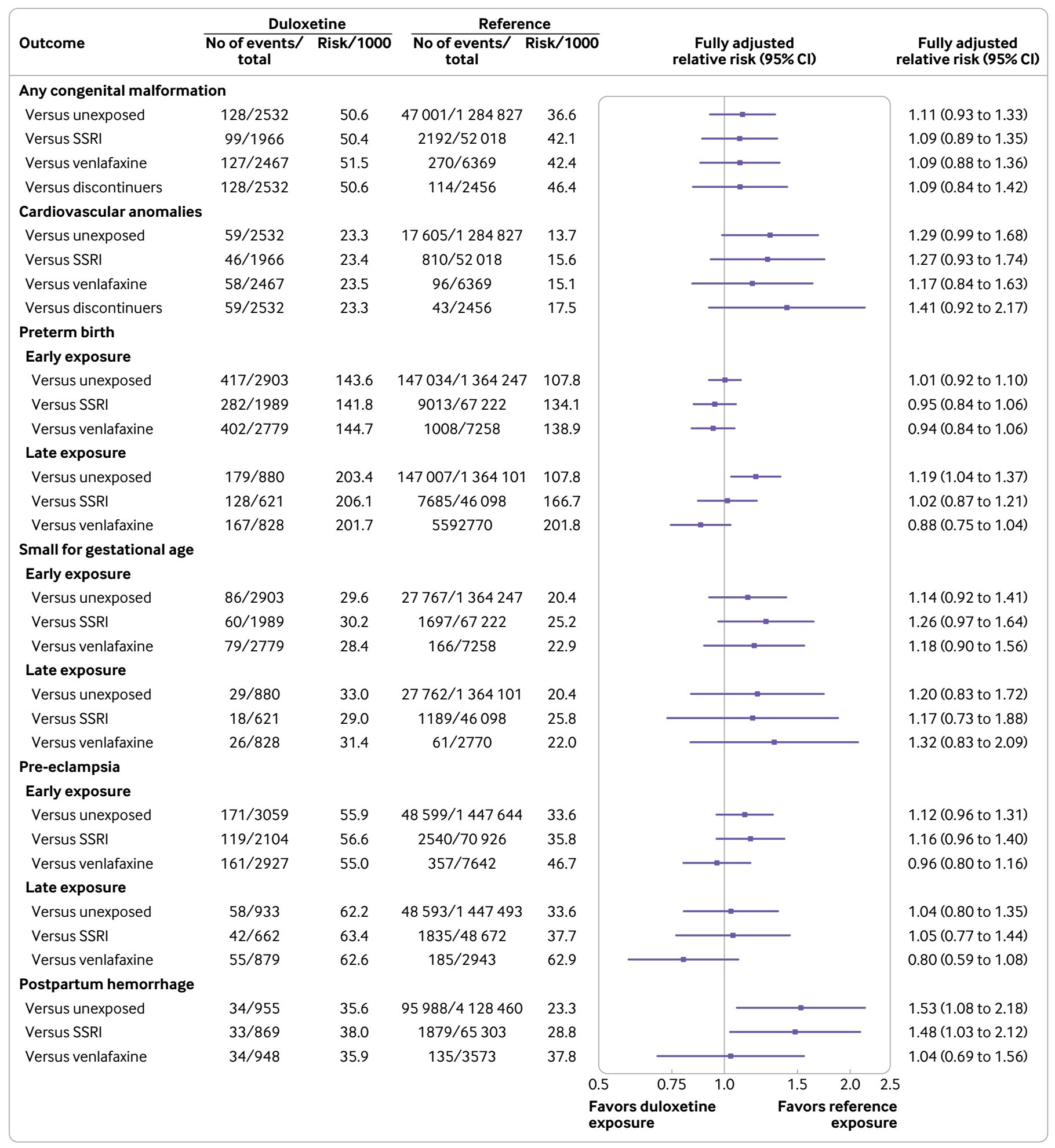

Fig 1 | Absolute risks and fully adjusted relative risks of adverse maternal and fetal outcomes, according to maternal exposure to duloxetine

exposed women: 0.95 (0.66 to 1.37 ) in unadjusted analyses, 1.11 ( 0.74 to 1.66 ) after restriction to and adjustment for treatment indication, 1.04 (0.69 to 1.56) after full adjustment, and 0.98 (0.65 to 1.47$)$ with hdPS adjustment (fig 1). Sensitivity analyses all had results consistent with those of the main analyses (increased risk when the referent was unexposed women or SSRI exposed women). These results, taken together, suggest an increased risk of postpartum hemorrhage, which seems to be a class effect of SNRIs (sFigures 18 and 19).

\section{Discussion}

Evidence from this large cohort study suggests that duloxetine is unlikely to be a major teratogen. Exposure to duloxetine during pregnancy is unlikely 
to meaningfully increase the risk of congenital malformations overall, preterm birth, or pre-eclampsia. Findings suggest an increased risk of postpartum hemorrhage, which was present also for venlafaxine, another SNRI. We identified a potential small increase in the risk of congenital cardiac malformations, but the relative risk was less than 1.3 , with the upper bound of the $95 \%$ confidence interval below a twofold increase in risk. Similarly, we identified a potential small increase in the risk of small for gestational age infants, but this association was not consistently observed in all sensitivity analyses.

\section{Comparison with other studies}

This is the first large controlled study examining the safety of duloxetine in pregnancy. Our conclusions are generally consistent with those from a systematic review including evidence published through April $2015 .^{6}$ Based on four cohort studies, the review identified 668 duloxetine exposed infants, of whom 16 were born with a major malformation, resulting in a malformation rate of $2.4 \% .{ }^{14518}$ Using a malformation rate of $3.0 \%$ in the background population as the reference, the authors estimated the relative risk at 0.80 (95\% confidence interval 0.46 to 1.29 ), leading to the conclusion that available data on duloxetine exposure during the first trimester do not support a substantially increased risk, although the authors acknowledge that the confidence intervals are fairly wide. Because of the use of an external reference group, little to no adjustment for confounding was made in this pooled estimate. $^{6}$

An increased risk of cardiac malformations associated with first trimester exposure to duloxetine has not previously been reported, but these malformations have long been at the center of the controversy about the safety of antidepressants overall and SSRIs in particular, ${ }^{19-24}$ and we therefore selected them as a primary outcome in our study. In the context of multiple comparisons and based on a small number of exposed cases $(<15)$, we observed an increased risk of urinary malformations (fully adjusted relative risk of 1.89 (1.14 to 3.14) versus unexposed women). Two of the 165 pregnancies exposed to duloxetine had urinary malformations in the study by Einarson, ${ }^{4}$ and venlafaxine exposure was associated with a relative risk of $1.43(0.75$ to 2.73) for urinary malformations in the Quebec Pregnancy Cohort. ${ }^{25}$ Thus, future studies should further explore the association between exposure to duloxetine and urinary malformations.

\section{Strengths and limitations of study}

This study has several strengths including the use of a large population based cohort representative of publicly insured pregnant women in the US, prospectively collected exposure information eliminating the potential for recall bias, availability of internal reference groups, ability to study a broad range of maternal and infant outcomes, and rich information for adjustment for confounding.
However, as is the case for any epidemiologic study based on healthcare utilization data, the study also has some limitations. Firstly, we had to estimate the date of the last menstrual period by using diagnostic information on preterm birth, which may have resulted in some misclassification of the exposure window for the congenital malformations cohort and some misalignment of the early versus late exposure windows for the preterm, small for gestational age, and pre-eclampsia cohorts. However, validation studies suggest that algorithm derived prenatal exposure to antidepressants has a sensitivity and a positive predictive value of at least $95 \%$ and a specificity and a negative predictive value of almost $100 \% .^{26}$

Secondly, not all women filling a prescription will necessarily take the drug as prescribed, which results in some misclassification of the exposure status. We countered this through the use of sensitivity analyses in which we required women to have filled at least two prescriptions during the etiologically relevant window (increasing the specificity of the exposure definition) or to have a day's supply that overlaps with the etiologically relevant window (increasing the sensitivity of the exposure definition). Although not perfect, short of pill counts or blood level measurements-neither of which is feasible in the context of the large scale studies needed to study drug safety in pregnancy-they are the best available measures of exposure status.

Thirdly, we ascertained outcomes on the basis of diagnostic and procedure codes recorded for reimbursement purposes, leading to potential misclassification of the outcome. To overcome this concern, we did an internal outcome validation study for those outcomes that had not previously been validated (that is, major congenital malformations other than cardiac, postpartum hemorrhage, preterm delivery, and small for gestational age infant). We linked pregnancies in MAX with the outcome of interest defined on the basis of diagnostic or procedure claims to medical records for patients who were treated at hospitals that are part of Partners Healthcare (which includes Brigham and Women's Hospital and Massachusetts General Hospital). We retrieved 50 medical records from pregnancies defined with these codes for each outcome, and two physicians who were blinded to the drug exposure status reviewed the charts according to established clinical criteria and classified the outcome as present or absent. We used the resulting positive predictive values to inform probabilistic bias analyses that generated corrected relative risk estimates. ${ }^{13}$ As a second approach to assess the robustness of our findings to outcome misclassification, we matched exposed to non-exposed women (from the primary analysis for each outcome, using the propensity score) in a 1:1 ratio for outcomes with a prevalence of at least $3 \%$ in the unexposed cohort and in a 1:5 ratio for outcomes with a prevalence of less than $3 \%$ by using a nearest neighbor algorithm. We generated de-identified claims profiles of mothers or infants with the outcome of interest as defined using 
the outcome algorithms for all cases in the matched cohort. Expert clinicians reviewed the profiles, blinded to the exposure status, and "adjudicated" each case as the outcome likely occurred, the outcome probably occurred, or the outcome likely did not occur. As we strived for high specificity of the outcome definition to ensure the that relative risk is unbiased, we assessed the effect of excluding either or both of the last two types of case on the relative risk estimates. Two clinicians reviewed each profile. Disagreements in the initial determination were resolved through discussion. Findings from both approaches to reduce outcome misclassification were generally consistent with those from the main analyses, taking the imprecision of some of the estimates into account.

Fourthly, despite the rich information available for adjustment for confounders, potential always exists for residual confounding in observational studies. We implemented several different approaches to minimize this possibility, including the use of alternative comparator groups (women exposed to other antidepressants, women exposed to duloxetine before but not during pregnancy) and the use of high dimensional propensity scores to adjust for proxies of unmeasured confounders. ${ }^{15}$ Additionally, we explored the effect of potential residual confounding by lifestyle factors poorly measured in claims data (that is, alcohol, smoking, and obesity) but available in external data such as the National Health and Nutrition Examination Survey (NHANES) by using binary algebraic solutions (see appendix (sFigures 20-24) for details). ${ }^{27}$

Fifthly, we used a cohort of pregnancies resulting in live birth, because no validated algorithms are available to estimate the gestational age in non-live births. Consequently, the risk of spontaneous abortion, termination, and stillbirth could not be studied using this cohort. Findings from a preliminary exploratory assessment of the association between duloxetine and pregnancy losses are reported elsewhere (www. encepp.eu). In addition, the restriction to live births may introduce selection bias if differences exist in the proportion of terminations between women treated with duloxetine and untreated women within levels of covariates used in the adjustment. We explored the potential effect of such selection bias by using methods proposed by Greenland and Khoury, ${ }^{28}$ 29 previously described in detail by our group. ${ }^{22}$ 27 Briefly, we modeled a range of non-livebirth frequencies for malformed infants in the unexposed and exposed cohorts and then calculated "corrected" relative risk estimates based on these inputs and the adjusted relative risk estimate from the main analysis. Conclusions about potential associations between duloxetine use and the various outcomes considered were informed by the main analyses as well as the broad range of sensitivity analyses conducted to test the robustness of the findings in light of potential threats to the study validity (misclassification, confounding, selection bias, and random error).

Our study population included pregnant women eligible for Medicaid, a young, racially diverse vulnerable population that is traditionally understudied. Unless the factors that distinguish other groups of pregnant women are believed to affect the biologic relations studied, the etiologic findings should be generalizable, although the magnitude of the relative risk may vary if the baseline risks vary across populations and the effect is additive (rather than multiplicative) ${ }^{\cdot 3} 0$

\section{Implications and future research}

Pregnancy exposure registries and epidemiologic studies that rely on real world evidence from healthcare utilization data to evaluate safety of drugs during pregnancy are complementary approaches, each having distinct strengths and weaknesses. Using a pregnancy cohort nested in the nationwide MAX data, we were able to add to the initial evidence on the risk of congenital malformations with duloxetine and to generate the first evidence on other maternal and fetal outcomes. We conclude that duloxetine is likely not a major teratogen but may be associated with small increases in the risk of cardiac malformations, postpartum hemorrhage, and possibly small for gestational age infants. Important directions for future research include the replication of these analyses using a different dataset but similar rigorous approaches to overcome the residual uncertainty from both random and potential systematic errors, continued surveillance as more data accumulate over time to increase precision and therefore our confidence in the findings, and the study of non-livebirth outcomes by using datasets with reliable information on the start of pregnancies ending in non-live births. Because MAX does not include information on lactation, questions about the safety of duloxetine use during lactation remain unanswered. Until such additional information becomes available, the potential small increases in risk of relatively uncommon outcomes that we observed must be weighed against the benefits of treating depression and pain during pregnancy for both the mother's and the infant's health, a trade-off that is likely to be different for each individual patient.

We gratefully acknowledge the contributions of Mengdong He, Sara Z Dejene, Devan D Bartels, David J Combs, Jennifer A Cottral, Sarah Rae Easter, Kathryn Gray, Stephanie H Guseh, Erica Holland, Sarah Lassey, Beryl L Manning-Geist, and Rebecca M Reimers to the outcome validation study and the outcome claims profile review.

Contributors: KFH conceptualized and designed the study, did the analyses, and drafted the initial manuscript. BTB and SHD conceptualized and designed the study, critically reviewed the results of analyses, and reviewed and revised the manuscript. HM and RL did the analyses and reviewed and revised the manuscript. $\mathrm{HL}$ and SM provided input to the study concept and design, critically reviewed the results of analyses, and reviewed and revised the manuscript. AP, LGB MFSF, and HPU critically reviewed the results of analyses and reviewed and revised the manuscript. All authors approved the final manuscrip as submitted. The corresponding author attests that all listed authors meet authorship criteria and that no others meeting the criteria have been omitted. KFH is the guarantor.

Funding: The study was funded by an unrestricted grant to Brigham and Women's Hospital from Eli Lilly and Company to provide supplemental evidence to the Cymbalta Pregnancy Registry on the maternal and fetal outcomes of interest specified in the Cymbalta post-marketing requirement. The pre-specified study protocol and full study report are available on the Encepp website. Brigham and 
Women's Hospital retained the right to publish this work, without influence from its sponsor.

Competing interests: All authors have completed the ICMJE uniform disclosure form at www.icmje.org/coi_disclosure.pdf and declare: the study was funded by an unrestricted grant to Brigham and Women's Hospital from Eli Lilly and Company; KFH was an investigator on grants from GSK and Pfizer outside the submitted work; BTB was an investigator on grants from Baxalta, Pfizer, GSK, and Pacira outside the submitted work and has received personal fees from Aetion and the Alosa Foundation outside the submitted work; SHD was an investigator on grants from GSK and Pfizer outside the submitted work and has received personal fees from Bayer outside the submitted work; HL, SM, MFSF, and HPU were employees of Eli Lilly during the conduct of the study; no other relationships or activities that could appear to have influenced the submitted work.

Ethical approval: The research was approved by the institutional review board of Brigham and Women's Hospital, which granted a waiver of informed consent (IRB 2017P001944).

Data sharing: No additional data available.

Transparency statement: The lead author affirms that the manuscript is an honest, accurate, and transparent account of the study being reported; that no important aspects of the study have been omitted; and that any discrepancies from the study as planned (and, if relevant, registered) have been explained.

Dissemination to participants and related patient and public communities: Aside from the study protocol and full study report being available on the Encepp website, there are no plans to disseminate the results of the research to study participants or the relevant patient community.

This is an Open Access article distributed in accordance with the Creative Commons Attribution Non Commercial (CC BY-NC 4.0) license, which permits others to distribute, remix, adapt, build upon this work non-commercially, and license their derivative works on different terms, provided the original work is properly cited and the use is noncommercial. See: http://creativecommons.org/licenses/by-nc/4.0/.

1 Hoog SL, Cheng Y, Elpers J, Dowsett SA. Duloxetine and pregnancy outcomes: safety surveillance findings. Int J Med Sci 2013;10:413-9. doi:10.7150/ijms.5213

2 The Cymbalta Pregnancy Registry. https://clinicaltrials.gov/ct2/show/ study/NCT01074151.

3 U.S. Food and Drug Administration. Postapproval Pregnancy Safety Studies - Guidance for Industry. 2019. https://www.fda.gov/Drugs/ GuidanceComplianceRegulatorylnformation/Guidances/default.htm.

4 Einarson A, Smart K, Vial T, et al. Rates of major malformation in infants following exposure to duloxetine during pregnancy: a preliminary report. J Clin Psychiatry 2012;73:1471. doi:10.4088/ JCP.12l08013

5 Källén B, Borg N, Reis M. The use of central nervous system active drugs during pregnancy. Pharmaceuticals (Basel) 2013;6:1221-86. doi:10.3390/ph6101221

6 Lassen D. Ennis ZN, Damkier P. First-Trimester Pregnancy Exposure to Venlafaxine or Duloxetine and Risk of Major Congenital Malformations: A Systematic Review. Basic Clin Pharmacol Toxicol 2016;118:32-6. doi:10.1111/bcpt.12497

7 Kjaersgaard MI, Parner ET, Vestergaard M, et al. Prenatal antidepressant exposure and risk of spontaneous abortion - a population-based study. PLoS One 2013;8:e72095. doi:10.1371/ journal.pone.0072095

8 Palmsten K, Huybrechts KF, Mogun H, et al. Harnessing the Medicaid Analytic eXtract (MAX) to Evaluate Medications in Pregnancy: Design Considerations. PLoS One 2013;8:e67405. doi:10.1371/journal. pone.0067405

9 de Abajo FJ, Rodríguez LA, Montero D. Association between selective serotonin reuptake inhibitors and upper gastrointestinal bleeding. population based case-control study. BMJ 1999:319:1106-9. doi:10.1136/bmj.319.7217.1106

10 Palmsten K, Hernández-Díaz S, Huybrechts KF, et al. Use of antidepressants near delivery and risk of postpartum hemorrhage: cohort study of low income women in the United States. BMJ 2013;347:f4877. doi:10.1136/bmj.f4877

11 Palmsten K, Huybrechts KF, Kowal MK, Mogun H, Hernández-Díaz Validity of maternal and infant outcomes within nationwide Medicaid data. Pharmacoepidemiol Drug Saf 2014;23:646-55. doi:10.1002/ pds. 3627

12 Cooper WO, Hernandez-Diaz S, Gideon P, et al. Positive predictive value of computerized records for major congenital malformations. Pharmacoepidemiol Drug Saf 2008;17:455-60. doi:10.1002/ pds. 1534

13 He M, Cottral JA, Bartels DD, et al. Validation of Algorithms to Identify Perinatal Outcomes in Large Claims Databases. Pharmacoepidemiol Drug Saf 2017;26:98-9.

14 Austin PC. Using the standardized difference to compare the prevalence of a binary variable between two groups in observational research. Commun Stat Simul Comput 2009;38:1228-34. doi:10.1080/03610910902859574

15 Schneeweiss S, Rassen JA, Glynn RJ, Avorn J, Mogun H, Brookhart MA. High-dimensional propensity score adjustment in studies of treatment effects using health care claims data. Epidemiology 2009;20:512-22. doi:10.1097/ EDE.0b013e3181a663cc

16 Desai RJ, Rothman KJ, Bateman BT, Hernandez-Diaz S, Huybrechts KF. A Propensity-score-based Fine Stratification Approach for Confounding Adjustment When Exposure Is Infrequent. Epidemiology 2017;28:249-57. doi:10.1097/ EDE 0000000000000595

17 Patorno E, Huybrechts KF, Bateman BT, et al. Lithium Use in Pregnancy and the Risk of Cardiac Malformations. N Engl] Med 2017:376:2245-54. doi:10.1056/NEIMoa1612222

18 Hudson JI, Wohlreich MM, Kajdasz DK, Mallinckrodt CH Watkin JG, Martynov OV. Safety and tolerability of duloxetine in the treatment of major depressive disorder: analysis of pooled data from eight placebo-controlled clinical trials. Hum Psychopharmacol 2005;20:327-41. doi:10.1002/hup.696

19 Louik C, Lin AE, Werler MM, Hernández-Díaz S, Mitchell AA. Firsttrimester use of selective serotonin-reuptake inhibitors and the risk of birth defects. N Engl J Med 2007;356:2675-83. doi:10.1056/ NEJMoa067407

20 Alwan S, Reefhuis J, Rasmussen SA, Olney RS, Friedman IM, Nationa Birth Defects Prevention Study. Use of selective serotonin-reuptake inhibitors in pregnancy and the risk of birth defects. N Engl J Med 2007;356:2684-92. doi:10.1056/NEJMoa066584

21 Wurst KE, Poole C, Ephross SA, Olshan AF. First trimester paroxetine use and the prevalence of congenital, specifically cardiac, defects: a meta-analysis of epidemiological studies. Birth Defects Res A Clin Mol Teratol 2010:88:159-70. doi:10.1002/bdra.20627

22 Huybrechts KF, Palmsten K, Avorn J, et al. Antidepressant use in pregnancy and the risk of cardiac defects. N Engl J Med 2014;370:2397-407. doi:10.1056/NEJMoa1312828

23 Pedersen LH, Henriksen TB, Vestergaard M, Olsen J, Bech $\mathrm{BH}$. Selective serotonin reuptake inhibitors in pregnancy and congenital malformations: population based cohort study. BM/2009·339.b3569 doi:10.1136/bmi.b3569

24 Greene MF. Teratogenicity of SSRIs--serious concern or much ado about little?N Engl J Med 2007;356:2732-3. doi:10.1056/ NEJMe078079

25 Bérard A, Zhao JP, Sheehy O. Antidepressant use during pregnancy and the risk of major congenital malformations in a cohort of depressed pregnant women: an updated analysis of the Quebec Pregnancy Cohort. BMJ Open 2017;7:e013372. doi:10.1136/ bmjopen-2016-013372

26 Li Q Andrade SE, Cooper WO, et al. Validation of an algorithm to estimate gestational age in electronic health plan databases. Pharmacoepidemiol Drug Saf 2013;22:524-32. doi:10.1002/ pds. 3407

27 Huybrechts KF, Bateman BT, Hernández-Díaz S. Use of real-world evidence from healthcare utilization data to evaluate drug safety during pregnancy. Pharmacoepidemiol Drug Saf 2019;28:906-22. doi:10.1002/pds.4789

28 Greenland S. Basic methods for sensitivity analysis of biases. Int J Epidemiol 1996;25:1107-16. doi:10.1093/ije/25.6.1107

29 Khoury MJ, Flanders WD, James LM, Erickson JD. Human teratogens, prenatal mortality, and selection bias. Am Epidemiol 1989;130:361-70. doi:10.1093/oxfordjournals.aje. a115342

30 Rothman KJ, Greenland S, Lash TL. Modern Epidemiology. 3rd ed. Lippincott Williams \& Wilkins, 2008

\section{Supplementary materials}

